\title{
Dental treatment needs among patients undergoing screening at a university-based dental institution in Kuantan, Pahang, Malaysia
}

\author{
Azlini Ismail ${ }^{1^{*}}$, Zurainie Abllah ${ }^{2}$ Nur Aishah Muhammad Radhi ${ }^{3}$, Syazalina Musa ${ }^{3}$, Mohd \\ Firdaus Akbar Abdul Halim ${ }^{4}$ \\ ${ }^{1}$ Department of Fundamental Dental and Medical Sciences, Kulliyyah of Dentistry, International \\ Islamic University Malaysia, Indera Mahkota, 25200 Kuantan, Pahang, Malaysia. \\ ${ }^{2}$ Department of Paediatric Dentistry and Dental Public Health, Kulliyyah of Dentistry, International \\ Islamic University Malaysia, Indera Mahkota, 25200 Kuantan, Pahang, Malaysia. \\ ${ }^{3}$ Kulliyyah of Dentistry, International Islamic University Malaysia, Indera Mahkota, 25200 Kuantan, \\ Pahang, Malaysia. \\ ${ }^{4}$ Faculty Computer and Mathematical Sciences, Universiti Teknologi MARA Kelantan Branch, Kota \\ Bharu Campus, Lembah Sireh, 15050 Kota Bharu, Kelantan, Malaysia.
}

\begin{abstract}
University-based dental institution in Malaysia receives large number of dental visits, however, dental treatment needs among patients attending this kind of institution is not usually reported. This study aimed to identify the trend of dental treatment needs in a university-based dental institution in Kuantan, Pahang situated in the East Coast region of Peninsular Malaysia. This cross-sectional study utilized secondary data, obtained from list of patients who underwent for screening at Outpatient Clinic, Kulliyyah of Dentistry, International Islamic University Malaysia from 1st January to 31st December 2016. Patient's age, gender, residential area and dental treatment needs were retrieved from the list. All patients were included except those with incomplete data, with old Malaysian identification card or foreign passport or those assigned to receive Orthodontic treatment. Descriptive statistics and Pearson's Chi Square test was run using SPSS ${ }^{\circledR}$ Version 20 software. Conservative care $(22.7 \%)$ was the major treatment need among 2,627 patients included in this study. Teenage and adult patients mostly required conservative care while the elderaged patients have major need for prosthodontics. Females outnumbered males in requiring all types of dental treatment, except for conservative care which was pre-dominantly required by males. Patients residing non-urban area majorly required all types of dental treatment except for endodontics and conservative care which were more frequently necessitated by patients from urban area. Conservative care was the major dental treatment need. The type of dental treatment needs has significant association with patient's age, gender and residential area.
\end{abstract}

Keywords: treatment need, screening, dental, age, gender

${ }^{*}$ Corresponding Author

Email address: $\underline{\text { dr azlini@iium.edu.my }}$

Tel: +6014-501 0081

\section{Introduction}

Need is classified into normative, felt, expressed or comparative needs according to Bradshaw (1972) taxonomy.
Normative need for dental treatment is a category of need which is usually defined by the experts or professional. However, the process of dental screening usually takes into consideration the felt or 
perceived need according to patients' complaints on their oral health conditions. Dental professional or a dental officer then assesses the suitability of dental treatment for the patients.

Dental treatment needs and the oral health status of Malaysians were periodically assessesed every ten years from 1990 to 2010 using National Oral Health Survey of Adults (NOHSA). Since 2010, the oral health status and dental treatment needs in Malaysia have not been assessed at any national scale study. In the meantime, there are local studies that studied on specific dental treatment need, for instance the orthodontic treatment need among various study populations including of school children aged 12 and 16 years old (Zreaqat et al., 2013), adolescents aged 13 to 14 years old (Zamzuri et al., 2014), adults aged 20 to 70 years old (Ravindranath et al., 2017) as well as among the special need people with Down Syndrome (Abdul Rahim et al., 2014). Nevertheless, there are also researches that analysed on general dental treatment needs in certain populations in Malaysia, for instance, among the special need children in Negeri Sembilan, a state which is situated in the centre of Peninsular Malaysia (Mokhtar et al., 2016); among normal (Oo et al., 2011) and hearingimpaired school children (Rahman et al., 2015) as well as among the elderly (Sinor, 2013; Sinor et al., 2018) in Kelantan, a state located in the North East Region of Peninsular Malaysia.

However, there is no specific study that has contextualizes the dental treatment needs based on any universitybased Malaysian dental institution. Dental Clinic at Kulliyyah of Dentistry, International Islamic University Malaysia which is established in 2006 is the only university-based dental service provider in the city of Kuantan, Pahang, Malaysia and it is one of the two university-based dental centres that cater for the East Coast region in Malaysia. The number of patients may reach up to 10,000 visits per year indicative for a high demand and need for dental treatment among the surrounding community. In view of this, this study aims to analyse the trend of major dental treatment need in this population.

\section{Materials and Methods}

\section{Study Location and Data Collection}

Ethical approval (IREC 762) was obtained from IIUM Research Ethics Committee. This study was conducted at IIUM Dental Outpatient Clinic in Kuantan, Pahang. Kuantan is the capital city of Pahang, situated at the East Coast region of Peninsular Malaysia. Our study population was all first-visit patients undergoing screening at IIUM Dental Outpatient Clinic from $1^{\text {st }}$ January 2016 until $31^{\text {st }}$ December 2016. Information on patient's age, gender, residential area and the type of dental treatment needs was retrieved from Outpatient Clinic database. Type of treatment needs were decided by dental officer in-charge at this clinic after carrying out the usual procedure of screening and dental charting for patient's oral health condition. Treatment need was then notified in the patient's folder, and was remarked into the Patient Waiting List of any departments according to their treatment needs. Patients with incomplete data or with old Malaysian identification card or foreign passport and those attended Orthodontic department are excluded.

For demographic profile analysis, patients were classified based on their age group, gender and residential area in Kuantan. Age were classified into six groups of 14 years old and below, 15 to 19 years old, 20 to 34 years old, 35 to 44 years old, 45 to 64 years old, and 65 years old and above. Residential areas were classified into urban and non-urban areas according to Kuantan Municipal 
Council. Dental treatment needs was classified as stated in the clinic database; endodontics (anterior), endodontics (posterior), fixed prosthetic (bridge), fixed prosthetic (crown), partial denture, full denture, paediatric dentistry, oral surgery, general dental practice, oral maxillofacial, conservative care and periodontal need.

\section{Statistical Analysis}

Descriptive statistics was used to analyze the demographic profiles of this population. Association of demographic background (age, gender and residential areas) with the type of dental treatment needs was analysed using Chi-Square test in SPSS ${ }^{\circledR}$ software Version 20.

\section{Results}

\section{Demographic Profiles}

Demographic profiles of first-visit patients at IIUM Dental Outpatient Clinic for the year 2016 are tabulated in Table 1. The major age group of patients was from the age of 20 to 34 years old $(39.5 \%)$ while the least number of patients was from the age group of 65 and above (4.2\%). The mean age of the patients was $32 \pm 17.61$ years old. Female patients $(55.5 \%)$ outnumbered male patients $(44.5 \%)$ with majority of patients residing non-urban areas $(37.6 \%)$.

\section{Dental Treatment Needs}

Figure 1 shows distribution of dental treatment needs in which the highest treatment need was conservative care $(22.7 \%)$ while the lowest treatment need was for oral maxillofacial care $(0.6 \%)$.

\section{Association of demographic profiles with types of dental treatment needs}

Table 2 shows cross tabulation of age with the type of dental treatment needs. There is significant association between age, $X^{2}(55, N=2,627)=$
$3,466.9, p<.0001$ with the type of dental treatment needs. Paediatric patients (age group of $\leq 14$ ) were almost exclusively assigned to receive paediatric dentistry care $(97.5 \%)$. Younger-age patients (age group of 15-19, 20-34 and 35-44) mostly required conservative care $(38.9 \%, 30.9$ $\%$ and $30.3 \%$, respectively), followed by periodontal need $(17.2 \%, 24.5 \%$ and $17.0 \%$, respectively). Elder-age patients (age group of $45-64$ and $\geq 65$ ) have major need for prosthodontics with $30.5 \%$ and $40.5 \%$, respectively for partial dentures and $9.4 \%$ and $31.5 \%$, respectively for full dentures. The need for partial dentures increases with increasing age, this is noticeable from the age group 35-44 (8.9 $\%), 45-64$ (30.5\%) and $\geq 65$ (40.5\%). This is also similar to the need for full dentures that begins from the age group of 45-64 $(9.4 \%)$ and drastically increased in the age group of $\geq 65$ (31.5\%).

In contrast, the need for oral surgery decreases with increasing age; the need was highest among patients from the age groups of 20-34 (17.9\%), 35-44 (16.7\%), 45-64 (9.6\%) and $\geq 65$ (8.1\%). The need for oral maxillofacial care is consistently low compared to other treatment needs across all age groups. This study also found that types of dental treatment needs also significantly differed by gender, $X^{2}(11, N=2,627)=49.8, p<$ .0001 . As cross tabulated in Table 3 , females outnumbered males in all types of dental treatment need, except for periodontal need which was predominated by males. The relation between residential areas and the type of dental treatment need was also significant, $X^{2}(11, \mathrm{~N}=2,627)=112.6, \mathrm{p}<.0001$.

As shown in Table 4, people residing non-urban areas outnumbered those residing urban areas in getting fixedprosthetic (bridge) (50.6\%), fixedprosthetic (crown) (58.5\%), partial denture $(60.0 \%)$, full denture $(79.1 \%)$, paediatric dentistry care $(62.3 \%)$, oral surgery $(57.6 \%)$, general dental practice $(52.6 \%)$ and periodontal care $(51.7 \%)$. 
Table 1. Demographic profiles of patients underwent for screening at IIUM Dental Outpatient Clinic for the year 2016.

\begin{tabular}{|c|c|}
\hline Demographic Profiles & n (\% of total) \\
\hline \multicolumn{2}{|l|}{ Age } \\
\hline$\leq 14$ & $434(16.5 \%)$ \\
\hline 15 to 19 & $157(6.0 \%)$ \\
\hline 20 to 34 & 1,037 (39.5 \%) \\
\hline 35 to 44 & $347(13.2 \%)$ \\
\hline 45 to 64 & $541(20.6 \%)$ \\
\hline \multirow[t]{2}{*}{$\geq 65$} & $111(4.2 \%)$ \\
\hline & Total $=2,627(100.0 \%)$ \\
\hline \multicolumn{2}{|l|}{ Gender } \\
\hline Male & $1,168(44.5 \%)$ \\
\hline \multirow[t]{2}{*}{ Female } & $1,459(55.5 \%)$ \\
\hline & Total $=2,627(100.0 \%)$ \\
\hline \multicolumn{2}{|l|}{ Residential Areas } \\
\hline Urban & $1,251(47.6 \%)$ \\
\hline \multirow[t]{2}{*}{ Non-urban } & $1,376(52.4 \%)$ \\
\hline & Total=2,627 (100.0\%) \\
\hline
\end{tabular}

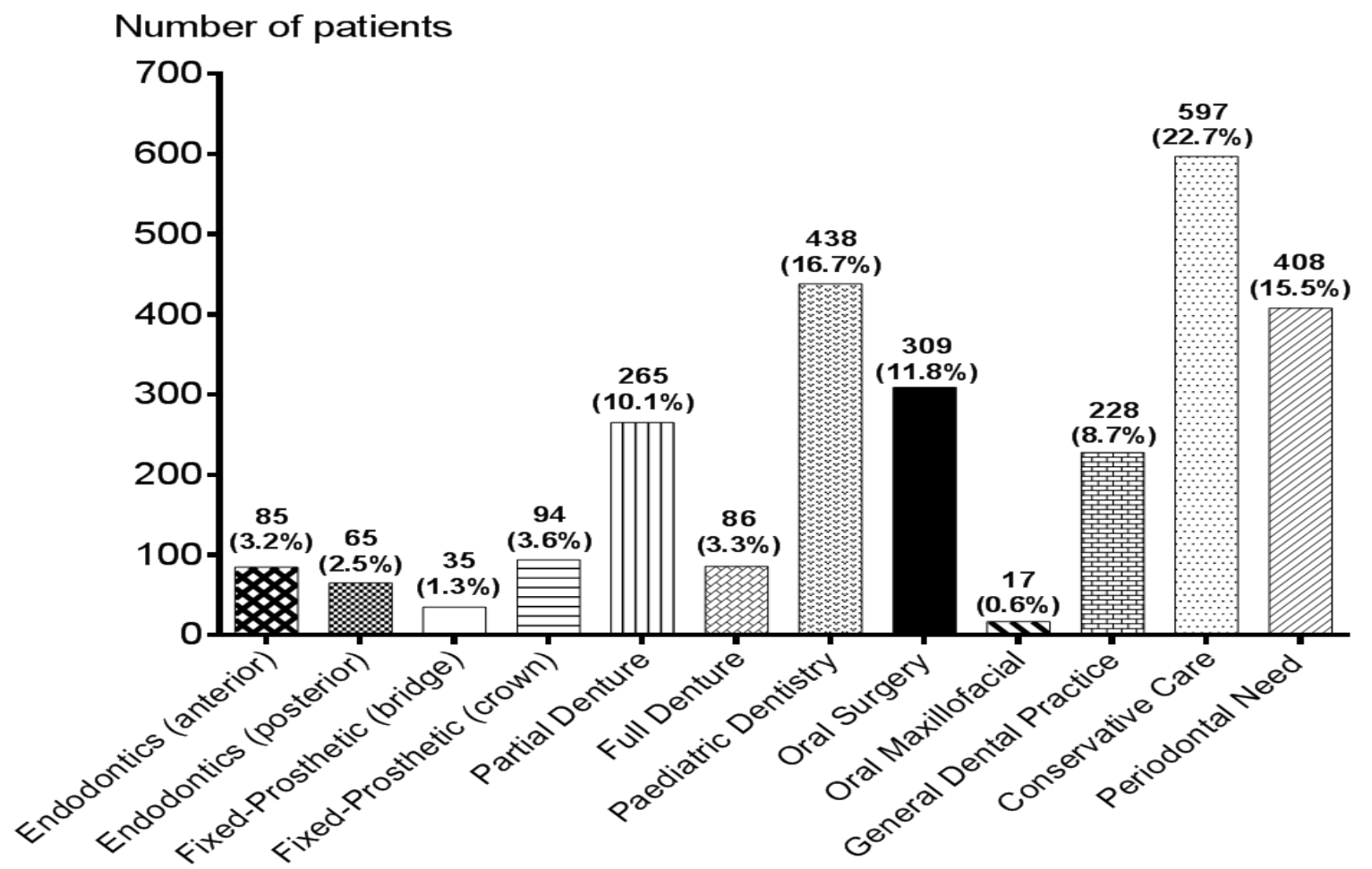

Dental Treatment Need

Figure 1. Distribution of dental treatment needs among patients underwent for screening at IIUM Dental Outpatient Clinic for the year 2016. 
Table 2. Cross tabulation of dental treatment needs versus age of patients underwent for screening at IIUM Dental Outpatient Clinic for the year 2016

\begin{tabular}{|c|c|c|c|c|c|c|c|c|c|c|c|c|c|c|}
\hline \multirow{2}{*}{$\begin{array}{c}\text { Age } \\
\text { group }\end{array}$} & \multicolumn{13}{|c|}{ Dental Treatment Needs } & \multirow{2}{*}{$\begin{array}{c}\text { Statistical } \\
\text { Analysis }\end{array}$} \\
\hline & $\mathbf{a}$ & b & C & d & e & $f$ & g & $\mathbf{h}$ & $\overline{\mathbf{i}}$ & $\mathbf{j}$ & $\mathbf{k}$ & I & Total & \\
\hline \multirow{3}{*}{$\begin{array}{l}\leq 14 \\
\text { Count } \\
\% \text { within } \\
\text { age } \\
\% \text { within } \\
\text { treatment }\end{array}$} & 0 & 0 & 0 & 1 & 0 & 0 & 423 & 0 & 0 & 3 & 2 & 5 & 434 & \multirow{9}{*}{$\begin{array}{c}X^{2}(55, \\
N= \\
2,627)= \\
3,466.9, \\
\mathbf{p}<.0001\end{array}$} \\
\hline & $0.0 \%$ & $0.0 \%$ & $0.0 \%$ & $0.2 \%$ & $0.0 \%$ & $0.0 \%$ & $97.5 \%$ & $0.0 \%$ & $0.0 \%$ & $0.7 \%$ & $0.5 \%$ & $1.2 \%$ & $100.0 \%$ & \\
\hline & $0.0 \%$ & $0.0 \%$ & $0.0 \%$ & $1.1 \%$ & $0.0 \%$ & $0.0 \%$ & $96.6 \%$ & $0.0 \%$ & $0.0 \%$ & $1.3 \%$ & $0.3 \%$ & $1.2 \%$ & $16.5 \%$ & \\
\hline \multirow{3}{*}{$\begin{array}{l}15 \text { to } 19 \\
\text { Count } \\
\% \text { within } \\
\text { age } \\
\% \text { within } \\
\text { treatment }\end{array}$} & 13 & 4 & 1 & 4 & 1 & 0 & 15 & 4 & 4 & 23 & 61 & 27 & 157 & \\
\hline & $8.3 \%$ & $2.5 \%$ & $0.6 \%$ & $2.5 \%$ & $0.6 \%$ & $0.0 \%$ & $9.6 \%$ & $2.5 \%$ & $2.5 \%$ & $14.6 \%$ & $38.9 \%$ & $17.2 \%$ & $100.0 \%$ & \\
\hline & $15.3 \%$ & $6.2 \%$ & $2.9 \%$ & $4.3 \%$ & $0.4 \%$ & $0.0 \%$ & $3.4 \%$ & $1.3 \%$ & $23.5 \%$ & $10.1 \%$ & $10.2 \%$ & $6.6 \%$ & $6.0 \%$ & \\
\hline \multirow{3}{*}{$\begin{array}{l}20 \text { to } 34 \\
\text { Count } \\
\% \text { within } \\
\text { age } \\
\% \text { within } \\
\text { treatment }\end{array}$} & 49 & 32 & 10 & 37 & 23 & 0 & 0 & 186 & 11 & 115 & 320 & 254 & 1,037 & \\
\hline & $4.7 \%$ & $3.1 \%$ & $1.0 \%$ & $3.6 \%$ & $2.2 \%$ & $0.0 \%$ & $0.00 \%$ & $17.9 \%$ & $1.1 \%$ & $11.1 \%$ & $30.9 \%$ & $24.5 \%$ & $100.0 \%$ & \\
\hline & $57.6 \%$ & $49.2 \%$ & $28.6 \%$ & $39.4 \%$ & $8.7 \%$ & $0.0 \%$ & $0.00 \%$ & $60.2 \%$ & $64.7 \%$ & $50.4 \%$ & $53.6 \%$ & $62.3 \%$ & $13.2 \%$ & \\
\hline
\end{tabular}

Note: Treatment a-Endodontics (Anterior), b-Endodontics (Posterior) c-Fixed-prosthetics (Bridge), d-Fixed-Prosthetics (Crown), e- Partial Denture, f-Full Denture, g-Paedodontics, h-Oral Surgery, i-Oral Maxillofacial, j-General Dental Practice, k-Conservative Care and I-Periodontal Need. Chi-square test, $X^{2}(55, N=2,627)=3,466.9, p<.0001$ 
Table 2. (Continued)

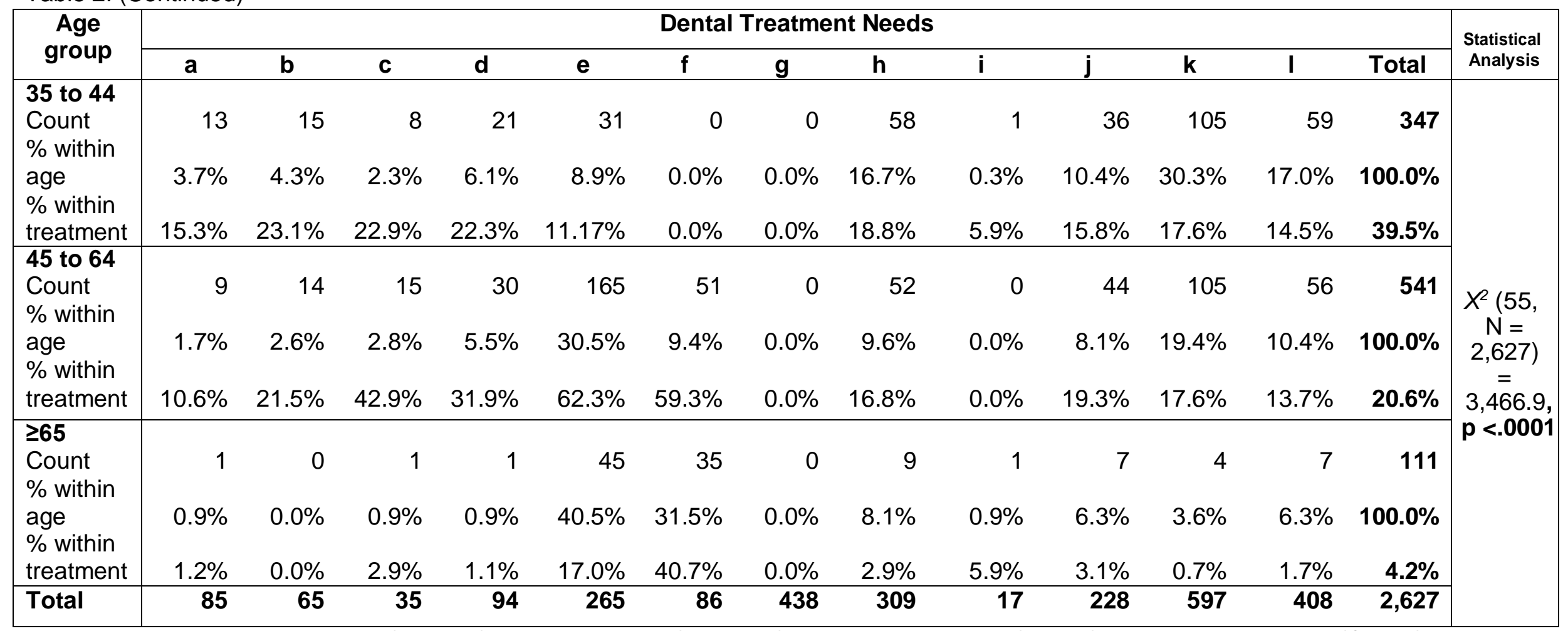

Note: Treatment a-Endodontics (Anterior), b-Endodontics (Posterior) c-Fixed-prosthetics (Bridge), d-Fixed-Prosthetics (Crown), e- Partial Denture, $\mathrm{f}$-Full Denture, g-Paedodontics, h-Oral Surgery, i-Oral Maxillofacial, j-General Dental Practice, k-Conservative Care and I-Periodontal Need. Chi-square test, $X^{2}(55, N=2,627)=3,466.9, p<.0001$ 
Table 3. Cross tabulation of dental treatment needs versus gender of patients underwent for screening at IIUM Dental Outpatie nt Clinic for the year 2016

\begin{tabular}{|c|c|c|c|c|c|c|c|c|c|c|c|c|c|c|}
\hline \multirow{2}{*}{ Gender } & \multicolumn{13}{|c|}{ Dental Treatment Needs } & \multirow{2}{*}{$\begin{array}{c}\text { Statistical } \\
\text { Analysis }\end{array}$} \\
\hline & $\mathbf{a}$ & b & C & d & e & $\mathbf{f}$ & g & $\mathbf{h}$ & $\mathbf{i}$ & $\mathbf{j}$ & $\mathbf{k}$ & I & Total & \\
\hline \multicolumn{15}{|l|}{ Male } \\
\hline $\begin{array}{l}\text { Count } \\
\text { \% within }\end{array}$ & 32 & 26 & 15 & 32 & 93 & 37 & 178 & 152 & 2 & 93 & 319 & 189 & 1,168 & \multirow{8}{*}{$\begin{array}{c}X^{2}(11, \\
N= \\
2,627) \\
=49.8, \\
p<.0001\end{array}$} \\
\hline $\begin{array}{l}\text { gender } \\
\% \text { within }\end{array}$ & $2.7 \%$ & $2.2 \%$ & $1.3 \%$ & $2.7 \%$ & $8.0 \%$ & $3.2 \%$ & $15.2 \%$ & $13.0 \%$ & $0.2 \%$ & $8.0 \%$ & $27.3 \%$ & $16.2 \%$ & $100.0 \%$ & \\
\hline treatment & $37.6 \%$ & $40.0 \%$ & $42.9 \%$ & $34.0 \%$ & $35.1 \%$ & $43.0 \%$ & $40.6 \%$ & $49.2 \%$ & $11.8 \%$ & $40.8 \%$ & $53.4 \%$ & $46.3 \%$ & $44.5 \%$ & \\
\hline \multirow{4}{*}{$\begin{array}{l}\text { Female } \\
\text { Count } \\
\text { \% within } \\
\text { gender } \\
\% \text { within } \\
\text { treatment }\end{array}$} & 53 & 39 & 20 & 62 & 172 & 49 & 260 & 157 & 15 & 135 & 278 & 219 & 1459 & \\
\hline & & & & & & & & & & & & & & \\
\hline & $3.6 \%$ & $2.7 \%$ & $1.4 \%$ & $4.2 \%$ & $11.8 \%$ & $3.4 \%$ & $17.6 \%$ & $10.8 \%$ & $1.0 \%$ & $9.3 \%$ & $19.1 \%$ & $15.0 \%$ & $100.0 \%$ & \\
\hline & $62.4 \%$ & $60.0 \%$ & $57.1 \%$ & $66.0 \%$ & $64.9 \%$ & $57.0 \%$ & $59.4 \%$ & $50.8 \%$ & $88.2 \%$ & $59.2 \%$ & $46.6 \%$ & $53.7 \%$ & $55.5 \%$ & \\
\hline Total & 85 & 65 & 35 & 94 & 265 & 86 & 438 & 309 & 17 & 228 & 597 & 408 & 2,627 & \\
\hline
\end{tabular}

Note: Treatment a-Endodontics (Anterior), b-Endodontics (Posterior) c-Fixed-prosthetics (Bridge), d-Fixed-Prosthetics (Crown), e- Partial Denture, f-Full Denture, g-Paedodontics, h-Oral Surgery, i-Oral Maxillofacial, j-General Dental Practice, k-Conservative Care and I-Periodontal Need. Chi-square test, $X^{2}(11, \mathrm{~N}=2,627)=49.8, \mathrm{p}<.0001$ 
Table 4. Cross tabulation of dental treatment needs versus residential area of patients underwent for screening at IIUM Dental Outpatient Clinic for the year 2016

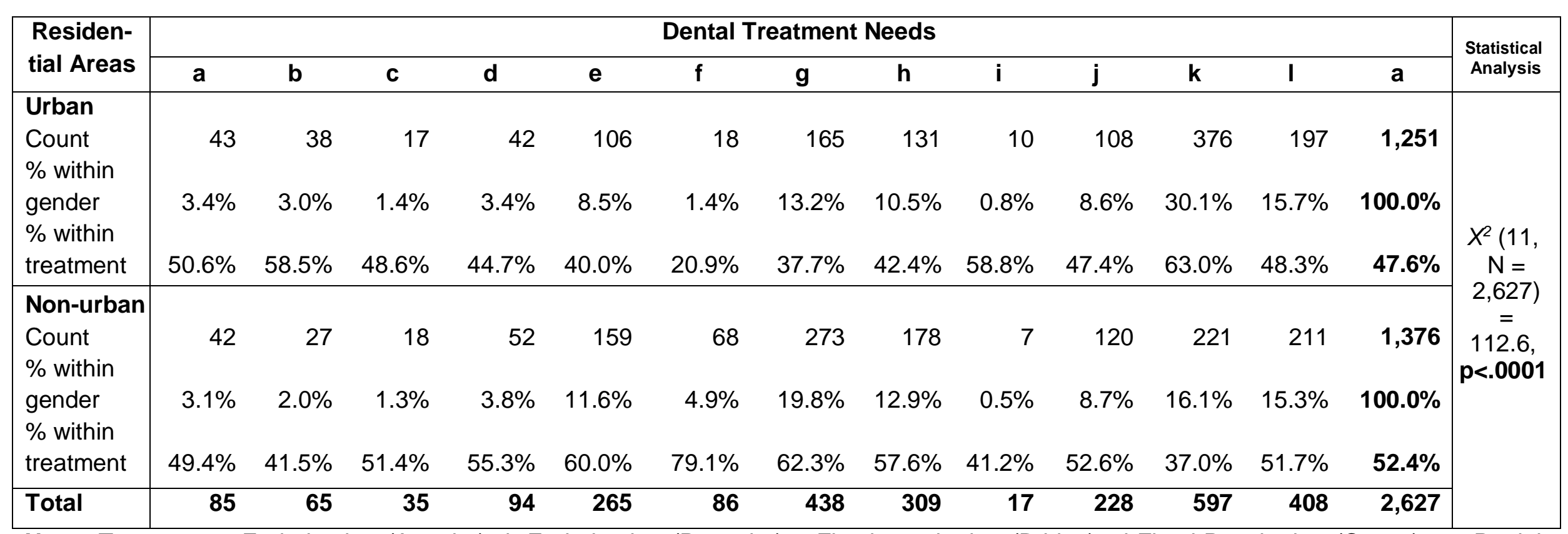

Note: Treatment a-Endodontics (Anterior), b-Endodontics (Posterior) c-Fixed-prosthetics (Bridge), d-Fixed-Prosthetics (Crown), e- Partial Denture, f-Full Denture, g-Paedodontics, h-Oral Surgery, i-Oral Maxillofacial, j-General Dental Practice, k-Conservative Care and I-Periodontal Need. Chi-square test, $X^{2}(11, \mathrm{~N}=2,627)=112.6, \mathrm{p}<.0001$. 


\section{Discussion}

The predominant need among teenage to adult patients was conservative care, followed closely by periodontal need. The main reason for the high demand for conservative and periodontal care was perhaps due to the high prevalence of caries and gingivitis among Malaysian adults. According to National Oral Health Survey of Adult (NOHSA) in 2010, about $94.0 \%$ of Malaysian adult population had periodontal disease while $88.9 \%$ of Malaysian population had dental caries experience.

This study also shows that majority of the first-visit patients at this clinic were females. This scenario was also observed in Turkish population (Pekiner et al., 2010), and in fact, a previous study in Southern China has also shown that females were more likely to visit dental service provider (Lo et al., 2001). Other than that, NOHSA 2010 also reported a higher proportion of females $(53.1 \%)$ that sought after dental treatment at public dental provider compared to males (49.3 $\%)$. This female predilection might be due to the difference of oral health between men and women, especially at certain age. The disparity in oral health increases between the genders as a population ages, which may relate to the combination of reproductive hormones influences, pregnancy, diet, as well as morning sickness during pregnancy in women (Lukacs, 2011). Other than pregnancy, menopause is also associated with increased risk of oral health complication, especially in women who developed osteoporosis (Branch-Elliman, 2012). Another plausible reason is that women visit more dental and oral health service providers because they usually are more attentive towards the aesthetics inclusive of the teeth (Akbar et al., 2019).

In addition to gender, age also have significant association with the type of dental treatment need. This study shows that younger-age patients mostly required conservative care while the elderage patients have major need for prosthodontics, either partial or full dentures. In agreement with this, prosthodontics was the most required treatment need among the elderly patients in Turkish (Pekiner et al., 2010) as well as in Northeast China (Liu et al., 2015) population. This study also shows that the need for partial and full dentures increases with increasing age. This is actually consistent with findings in NOHSA 2010 in which the study has shown that the number of edentulous significantly increases from the age of $35(1.1 \%)$ to the age 65 (35.6\%) and 75 (53.3\%). When the patient becomes edentulous, then the need for tooth extraction is nullified. The need for oral maxillofacial care which includes treatment for temporomandibular joint symptoms, operculectomy, pericoronitis and bruxism is consistently low compared to other treatment need across all age groups.

Residential area also has significant association with the type of dental treatment need. This study shows that people residing non-urban areas outnumbered those residing urban areas to receive fixed prosthetics of either bridge or crown; partial and full dentures; paedodontic care; periodontal treatment; and being referred to oral surgery and general dental practice departments. In general, people living in rural areas tend to have lower oral health problem, has more caries and fewer teeth compared to the urban residents (Akbar et al., 2019). However, the geographical location of this dental institution and the convenient of transportation made this institution still accessible to both the urban and nonurban residents.

\section{Conclusion}

Conservative care was the major dental treatment need identified in this study population. The type of dental treatment 
need has significant association with patient's age, gender and residential area. This finding substantially helps in understanding of dental treatment need, especially within the context of a university-based dental care provider in the East Coast region of Peninsular Malaysia.

\section{Acknowledgement}

We are also thankful to Mrs. Sa'diah, the Head Officer of Kuantan Municipal Council, as well as to our dental surgical assistant for her support during data retrieving at the clinic.

\section{References}

Abdul Rahim, F. S., Mohamed, A. M., Nor, M. M., \& Saub, R. (2014). Malocclusion and orthodontic treatment need evaluated among subjects with Down syndrome using the Dental Aesthetic Index (DAI). The Angle Orthodontist, 84(4), 600-606.

Akbar, F. H., Pasinringi, S., \& Awang, A. H. (2019). Relationship between health service access to dental conditions in urban and rural areas in Indonesia. Pesquisa Brasileira em Odontopediatria e Clínica Integrada, 19, 1-7.

Bradshaw, J. (1972). Taxonomy of social need. In G. McLahlan (Ed.), Problems and progress in medical care. London: Oxford University Press. 69-82.

Branch-Elliman, D. (2012). A gender-based approach to oral health changes across the lifespan. University of Pennsylvannia, USA.

Liu, L., Zhang, Y., Wu, W., \& Cheng, R. (2015). Characteristics of dental care-seeking behavior and related sociodemographic factors in a middle-aged and elderly population in Northeast China. BMC Oral Health, 15(1), 66.

Lo, E., Lin, H., Wang, Z., Wong, M., \& Schwarz, E. (2001). Utilization of dental services in Southern China. Journal of Dental Research, 80(5), 1471-1474.

Lukacs, J. R. (2011). Sex differences in dental caries experience: Clinical evidence, complex etiology. Clinical Oral Investigations, 15(5), 649-656.

Mokhtar, S. M., Jalil, L. A., Noor, N. M., Tan, B., Shamdol, Z., \& Hanafiah, H. A. (2016). Dental status and treatment needs of special needs children in Negeri Sembilan, Malaysia. World Journal of Research and Review, 2(6), 64-70.
National Oral Health Survery of Adults (NOHSA). Oral Health Division, Ministry of Health, Malaysia.

Oo, M. M. T., Naing, L., Mani, S. A., \& Ismail, A. R. (2011). Dental caries experience and treatment needs in the mixed dentition in North East Malaysia. Archives of Orofacial Sciences, 6(2), 41-48.

Pekiner, F., Gumru, B., Borahan, M. O., \& Aytugar, E. (2010). Evaluation of demands and needs for dental care in a sample of the Turkish population. European Journal of Dentistry, 4(2), 143-149.

Rahman, N. A., Yusoff, A., Daud, M. K. M., \& Kamaruzaman, F. N. (2015). Salivary parameters, dental caries experience and treatment needs of hearing-impaired children in a special school for deaf in Kelantan, Malaysia. Archives of Orofacial Sciences, 10(1), 17-23.

Ravindranath, S., En, J. T. S., \& Heng, A. P. K. (2017). Orthodontic treatment need and self-perceived psychosocial impact of dental esthetics in a university adult population in Malaysia. Journal of Indian Orthodontic Society, 51(2), 69-74.

Sinor, M. Z. (2013). Oral health assessment among elderly staying in shelter (Rumah Seri Kenangan), Kelantan, Malaysia. Age, 71, 8-38.

Sinor, M. Z., Ahmad, B., Ariffin, A., \& Hassan, A. (2018). Main medical illness, oral health complaints and treatment in elderly patients attending Hospital Universiti Sains Malaysia (HUSM) Dental Clinic. International Medical Journal, 25(4), 230232

Zamzuri, S. Z. M., Razak, I. A., \& Esa, R. (2014). Normative and perceived need for treatment of malocclusion among Malaysian adolescents. Sains Malaysiana, 43(7), 1037-1043.

Zreaqat, M., Hassan, R., Ismail, A. R., Ismail, N. M., \& Aziz, F. A. (2013). Orthodontic treatment need and demand among 12-and 16 yearold school children in Malaysia. Oral Health and Dental Management, 12(4), 217-221. 